\title{
APRENDENDO A SELECIONAR NA INTERNETO QUE É ÚTIL PARA A SUA PRÁTICA PROFISSIONAL
}

\author{
LEARNING TO SELECT ON THE INTERNET WHAT IS USEFUL FOR YOUR PROFESSIONAL PRACTICE
}

Reginaldo Holanda Albuquerque

DOI - 10.5935/2236-5117.2015v52n3/4a13

\section{RESUMO}

A comunicação eletrônica é uma realidade no mundo atual e tem vários benefícios, mas deve ser usada com cautela porque pode conter informações erradas a propósito da saúde. 0 autor faz interessante reflexão em relação ao uso das informações médicas na internet, tanto para o profissional de saúde, quanto para o leigo.

Palavras-chave. Comunicação eletrônica; informações na internet; relação médico-paciente

\section{ABSTRACT}

Electronic communication is a reality in today's world and has several benefits, but it should be used with caution because it may contain wrong information about health. The author makes an interesting reflection regarding the use of medical information on the Internet, both for the health professional and for the lay person.

Key words. Electronic communication; information on the internet; physician-patient relationship

A comunicação eletrônica vem trazendo mudanças significativas na prática médica e isto é mais uma forma de estresse na difícil relação médico-paciente.

Informação nem sempre é conhecimento, Conhecimento é a informação trabalhada, analisada, criticada. Outro problema é como transferir o conhecimento para a prática do dia a dia. O que é publicado ou visto nos noticiários, na maioria das vezes, não tem aplicação imediata nos consultórios médicos como pensam os clientes. São estudos experimentais ainda sem validação clínica ou mesmo materiais de divulgação de empresas produtoras de medicamentos.

A explosão da informação é de tal ordem na área de saúde que ela dobra a cada três anos. Além disso, existem outras pressões sobre os profissionais, como por exemplo:
Reginaldo Holanda Albuquerque - médico, endocrinologista

Correspondência: SGAS 915 Ed. Advance 1, sala n. ${ }^{\circ} 37$, CEP 70390-150, Brasília-DF. Telefone (61) 32452759.

Internet: reginaldo.albuquerque@gmail.com

Conflito de interesses: nada a declarar pelo autor.

Observação: Em atenção à vontade do autor, este artigo não foi editado pela equipe da Brasília Médica.

- Mais de 1.000 novas drogas são lançadas por ano.

- 250 mil novos artigos científicos por ano são publicados.

- Existem hoje 2.160 exames de laboratório que podem ser solicitados e que precisam ser corretamente interpretados.

- A pressão por redução de custo.

- As diretrizes, consensos e as posições das sociedades científicas que devem ser seguidas.

- As exigências de padrões mínimos de qualidade a serem atingidos na atividade médica.

- A internet como veículo de (des)educação da população.

É preciso lembrar que a prática médica é complexa e não depende só da informação e do conhecimento, mas também da capacidade de julgamento do médico e da sua habilidade de interagir com o paciente, como sugerido por Stephan Piaget, em 1909, na obra "A prática é a ciência tocada com emoção". A verdadeira "sabedoria médica" é a capacidade de compreender um problema clínico não em um órgão, mas em um ser humano integral.

A nova abordagem médica deve utilizar todos os recursos atuais que a informática proporciona, de modo a tornar os pacientes cada vez mais responsáveis pelos cuidados com a sua saúde.

Não é por outra razão, que revistas e jornais leigos em todos os países abordam nas suas edições semanais 
cada vez mais assuntos de saúde. O problema que surge diante dessa pletora de informação, tanto para os profissionais como para o público em geral é: como reconhecer a informação confiável e qual a relevância que tem dentro do contexto da patologia que está sendo estudada.

Neste sentido, a mais importante biblioteca médica americana, a National Library of Medicine, divulgou no seu site uma série de "dicas" para que as pessoas possam mais facilmente reconhecer na internet a confiabilidade dos sites.

O material pode ser encontrado no seguinte link: http://www.nlm.nih.gov/medlineplus/webeval/ webeval_start.html

Na verdade é um tutorial que abre com uma importante frase: "procurar informação sobre saúde na internet é como fazer uma caça a um tesouro, poderemos encontrar maravilhosas jóias ou terminarmos em lugares estranhos ou perigosos".

E prossegue ensinando como verificar se um site é confiável. Mostra com bela montagem dois sites com todos os bons e maus predicados. E finaliza sugerindo a seguinte lista de controle.

\section{PONTOS QUE_VOCÊ DEVE PROCURAR NUMM SITE DE SAUDE}

1. Quem ou qual é a organização responsável pela informação.

2. Você pode contatá-los?
3. De onde vem os recursos para a manutenção do site?

4. De onde vêm as informações que são veiculadas no site?

5. Como o conteúdo é selecionado?

6. A informação é revista por especialistas?

7. Está atualizado?

8. 0 site evita divulgação de material emocional ou que não tenha credibilidade?

9. O site pede suas informações pessoais e explica como pode usá-las?

10. Você tem confiança que sejam usadas como dizem?

\section{O PAPEL DO E-MAIL}

É o instrumento ou a ferramenta mais importante que apareceu depois do telefone para o desenvolvimento de relacionamentos interpessoais. É um meio meditativo, assíncrono, barato e que permite autodocumentação.

A comunicação por e-mail com o paciente resolve muitos problemas evitando a visita desnecessária ao consultório médico. Embora a maioria dos médicos tenha endereços eletrônicos, sabemos que somente $30 \%$ a $40 \%$ dos mesmos costumam usá-los e somente $20 \%$ o abrem nas primeiras 24 horas após recebê-lo. 